\title{
Exploration of Everydayness in Schizophrenia: A Phenomenological Approach
}

\author{
Sarah Troubé \\ Department of Psychology, Université Côte d'Azur, LIRCES, Nice, France
}

\section{Keywords}

Schizophrenia - Phenomenology · Subjective experiences .

Everydayness · Narrative

\begin{abstract}
This article explores everydayness as a specific form of experience of the world and its alterations in schizophrenia. In the field of phenomenological psychopathology, the transformations of subjective experience in schizophrenia have been the subject of a great deal of work, but the relationship between these alterations of subjective experience and the experience of the everyday remains largely unexplored. A phenomenological point of view leads us to explore everydayness as a constitutive framework of experience, one that may be impeded in schizophrenia. The question of the everyday allows us to bridge the gap between the descriptions of subjective experience proposed by phenomenological psychopathology and what is at stake in therapeutic treatment. It seems to us that the work of constructing an individual narrative of the everyday may be a useful psychotherapeutic approach for helping patients rebuild the framework of everydayness.

(c) 2020 S. Karger AG, Basel
\end{abstract}

(C) 2020 S. Karger AG, Basel

www.karger.com/psp

Karger $\stackrel{\text { ! }}{*}$

\section{Introduction}

The notion of the everyday very often bears a negative connotation, as being insignificant and trivial. This is perhaps the reason that it has been explored very little not only in the history of philosophy and social sciences, but also in psychopathology and psychiatry. However, it is in terms of its repercussions on the daily life of a person that a pathology is considered to be disabling. The assessment of quality of life, psychosocial rehabilitation, and recovery, which are the subject of a great deal of work, place the patient's ability to find autonomy in a daily framework at the heart of mental health care today $[1,2]$. What is often at issue in schizophrenia in particular is the difficulty of re-establishing a rhythm and automaticity in activities that act as a daily framework and reintegrate the subject into an intersubjective temporality [3].

The everyday has recently gained renewed interest in phenomenology thanks, in particular, to the work of the French philosopher Bruce Bégout [4]. Bégout questions the subjective constitution of the everyday using the notion of "everydaying" (quotidianisation), defined as the process that transforms being in the world into a familiar and ordinary experience. Everydayness (la quotidien-

Sarah Troube

Department of Psychology, Université Côte d'Azur

98 Boulevard Edouard Herriot

FR-06200 Nice (France)

sarah.troube@univ-cotedazur.fr 
neté), according to Bégout, appears as a pre-reflective framework of experience, one that should therefore not be confused with the norms of social adaptation and the empirical organization of the everyday (le quotidien) in each society. This empirical organization concerns the way in which everyday life is organized in a society: for example, the rules of socialization, the functioning of the family unit, the organization of work time, or eating practices.

What then does a phenomenological understanding of everydayness contribute to psychopathology, and in particular to an understanding of schizophrenia? The question of the everyday has been raised in the social sciences, especially in research done by Bourdieu [5], De Certeau [6], and Berger and Luckmann [7]. Using Schütz's work, Berger and Luckmann have traced connections between the social sciences and the phenomenological perspective. In the field of phenomenological psychiatry, it is Blankenburg who, also drawing inspiration from Schütz, has most worked on the everyday in connection with the notion of common sense, in what he calls the loss of natural self-evidence in schizophrenia [8]. In order to conceive of the everyday, Blankenburg relies on Husserl's notion of lifeworld (Lebenswelt) [9]. This is in contrast to Binswanger who, for his part, approaches the everyday via Heidegger's "They" in his analysis of distortion, presumption and mannerism [10].

More recently, the EASE [11] and EAWE [12] scales have proposed a detailed exploration of some alterations in the experience of self and world in schizophrenia in connection with the hypothesis that there has been a disturbance of the pre-reflexive minimal self. However, the specific relationship between everydayness and these alterations of the constitution of experience in schizophrenia has not yet received focused attention. This is what we propose to explore by identifying the different phenomenological dimensions of everydayness. The subjective experiences of schizophrenia seem to us to demonstrate an impairment of everydayness as a constitutive framework of experience.

\section{A Phenomenological Perspective: From the Everyday to Everydaying}

If everyday life is generally seldom questioned, it is because it possesses a specific phenomenological quality: it manifests itself as that which goes without saying and which remains implicit. It would thus concern the register of the self-evident and the pre-given, which Husserl

Exploration of Everydayness in

Schizophrenia develops with his notion of lifeworld (Lebenswelt) [9]. Constituted through passive syntheses, the lifeworld results from the sedimentation of perceptions and actions into habits. Through a pre-intentional process of synthesis and typification, these lived experiences are transformed into typical patterns of perception and action. These patterns then become an a priori framework for anticipation, a pre-given horizon for any new experience. These passive syntheses are thus what is behind the feeling of familiarity, so that an object, even a new one, already appears to the subject as having the form of something known [13]. The constitution of the everyday can thus be related to this structure of the lifeworld: insofar as it is made up of this sedimentation of habits, the everyday forms an implicit background for every new experience.

More specifically, Bégout [4] questions the conditions of the constitution of the everyday. To this end, he distinguishes between everydayness (la quotidienneté) as a constitutive framework of subjective experience, and the everyday (le quotidien), which concerns the empirical organization that everyday life can take on according to different cultures and subjects. Everydayness does not refer to objects or activities, but rather to a way of appearing, or to a specific form of presence in the world. It is what gives an experience a familiar and self-evident character, and in this sense, it forms a structure of pre-reflexive anticipation.

Unlike Heidegger, who considers the everyday to be a form of inauthentic existence in the discourse of the “They", [14] Bégout relates everydayness to Dasein's need to maintain itself in its being, which requires a stabilization and continuity of experience. The constitution of the everyday is thus a process of "domesticating" experience, which replaces the unknown and the indeterminacy of transcendence with the security of a delimited, predictable and familiar world: "in the everyday world, the everyday covers the world" [4, p. 170]. Bégout proposes to name this process everydaying (quotidianisation) or everydaying force (force quotidianisante). This framework of everydayness (quotidienneté) appears as both constituted and constitutive: constituted by the sedimentation of past experiences, it is also constitutive because it configures every new experience as being already familiar.

Through everydayness, the subject makes use of the world in the mode of practical habits and common sense, as a set of typical and pragmatic patterns of knowledge that constitute shared evidence - what Straus called the axioms of everyday life [15]. According to the analyses of Blankenburg [16] and Berger and Luckmann [7], everydayness appears to be closely linked to the constitution of 
common sense. The latter could be thought of as the result of a sedimentation of everydayness within the historical and cultural world. Serving as a framework for the practical understanding of experience, common sense would thus form a bridge between the pre-reflexive dimension of everyday life and the social world of an individual [17].

Bégout's hypothesis is that this force of everydaying conceals its constituted character: the power of the normative value and self-evident character of the everyday comes from the fact that it is experienced by the subject as pre-given, natural, and unchanging, whereas it is in fact the result of an ever-precarious process of domestication. Even though they are constituted by passive syntheses, the axioms of everyday life and natural self-evidence are manifest in experience as going without saying. The everyday is the source of the natural attitude, which suspends any doubt about reality. This natural attitude makes us forget that in the original experience, the transcendence of the world manifests itself with strangeness and unpredictability. Bégout therefore understands this pre-given character as being the result of an invisible magic trick, by which the process of constitution conceals itself.

This hypothesis has important implications for psychopathology. This process of passive and pre-reflective constitution of the everyday is fragile: familiarization is always likely to give way to the strangeness and indeterminacy of the world. Can this hypothesis help us to understand how these natural self-evidence can be lost in psychopathology, as well as how the patient can try to reconstitute them? Can it be said that schizophrenia is characterized by a specific disturbance of this process of everydaying?

\section{An Analysis of Some Dimensions of Everydayness}

In an effort to investigate the contributions of a phenomenology of everydayness to psychopathology, we have attempted to distinguish several dimensions of this everydayness on the basis of Bégout's work $[18,19]$. These dimensions can serve as a guide in the clinical exploration of a patient's difficulties with the everyday, and, more specifically, allow us to examine the functions of this framework of everydayness. Let us then examine four main dimensions of the constitution of this everydayness:

(1) The dimension of repetition: the everyday corresponds to a specific experience of lived time made possible by the repetition, regularity, and rhythmicity of the activities and events that make up daily existence. Made up of routines, rituals and habits, everydayness would make it possible to establish recurring patterns of anticipation by means of repetition. In its pre-reflexive, constitutive function, this dimension corresponds to the sedimentation at work in passive synthesis.

(2) The dimension of implicit normativity associated with a tacit sense of belonging or of community: the everyday is that by which an individual grounds himself in a lifeworld and in shared norms and values. In this way, everydayness would be constitutive of a specific form of intersubjectivity, which can be related to Heidegger's notion of readiness-to-hand [14]: an object always has a background of meanings, uses and values that are tacitly shared in a community. The function of the everyday is to guarantee these shared uses and affordances.

(3) The dimension of plasticity or adjustment: the very nature of the everyday is to constitute a framework that must remain at once flexible and constantly adjustable. The everyday is above all the framework for practical activities, and must constantly adapt to the emergence of the unexpected. Through this dimension of plasticity, everydayness would make it possible to domesticate what Maldiney calls transpassibility and transpossibility [20], i.e., the openness to a transcendence of experience that always goes beyond possibilities defined a priori. The flexible framework of the everyday, undergirded by the interplay of transpassibility and transpossibility, is that by which the event can be received in a familiar space: the already known resonates with the unexpected.

(4) The dimension of neutrality: the everyday is par excellence that which is not an event. Through its familiar routine, it transforms what makes for an event into a neutral element that is no longer salient for the subject, that does not require focused attention and does not involve decisive existential choices. Everydayness constitutes a background of neutrality on which events can stand out, forming a horizon of anticipation for the attribution of motivational salience.

These dimensions help to identify everydayness more precisely in its constitutive function as a framework of experience. Everydayness makes the constitution of a distinctive form of subjective experience possible by constituting a specific domestication of temporality, intersubjectivity and transpossibility. This work of domestication allows daily life to be given to the subject as a delimited, reliable, and reassuring sphere of experience.

We can then say with Bégout that the process of everydaying lies in an ever-fragile balance between two poles. At one end of the spectrum lies immobilization, the pure
Troubé 
determination of the return of the same, and a stereotyped framework, and at the other, transcendence, the pure indeterminacy of the event, and novelty. In other words, everydayness is a dialectical process between these two poles that must constantly find an intermediary between a withdrawal into the all-too-familiar - which would remove from life all openness to the unknown and to possibility - and a pure openness to the foreign and to transcendence - which would prevent the constitution of both stable points of reference and a familiar rhythm. The everyday must be able to constitute itself as a repetitive and neutral framework, while at the same time establishing a relationship with the event, the unknown, and the indeterminate.

The alterations of the everyday that are encountered in psychopathology can then be considered as disturbances of this dialectic of everydayness, where everydayness would fail to constitute this intermediate and reassuring space between the two poles. The alterations of experience that occur in schizophrenia can be traced back to these four dimensions of everydayness.

\section{Impairments of Everydayness in Schizophrenia}

In his discussion of the case of Anne, a patient who coined the term "natural self-evidence", Blankenburg highlights the difficulty in schizophrenia of constituting a daily framework as well as the close link between natural self-evidences and everydayness: "She always wanted answers to 'questions', for example, questions about becoming an adult, about the nature of her troubles, but also about how to find one's way around the most common notions and small evidences of everyday life" $[8$, p. 74$] .{ }^{1}$ Without the pre-given framework of everydayness, the relationship to the world rests solely on the empirical ego without any transcendental foundation. This is what gives rise to the experience of perplexity and exhaustion that Blankenburg calls transcendental asthenia.

Nevertheless, the relationship between the alterations of subjective experience in schizophrenia, as described by phenomenological psychopathology, and everydayness has not yet been sufficiently explored. If there is a disturbance of the minimal self and of the pre-reflective conditions of experience $[11,12]$, this disturbance must have consequences for the shaping of the framework of everydayness, which is at once constituted and constitutive. We can thus hypothesize that the constitutive dimension of

\footnotetext{
Our translation.
}

Exploration of Everydayness in Schizophrenia everydayness is affected in schizophrenia. Thus, everydayness cannot operate as a dialectic that creates an intermediate space between the pole of pure determination of the same and the pole of pure transcendence of the unexpected. It seems that the alterations of experience typical of schizophrenia can be linked to these two extreme poles. They thus reveal the failure of both this intermediate sphere and the dialectic of the familiar and the unknown proper to everyday life. These two extreme poles can be traced back to the different dimensions we have identified.

The dimension of repetition through which everydayness constitutes a specific experience of lived time seems unable to be constituted in schizophrenia. It is instead replaced either by an experience of time lived as automatic, stereotyped, and reified, or, at the opposite extreme, by an experience of pure and ceaseless novelty, in which nothing can be inscribed in a repetition [21], or else by a pure succession of moments without continuity [22]. Here, repetition cannot play its role of sedimenting past experiences, which would make it possible to constitute a horizon for anticipating new experiences. This failure of repetition can be linked to neurocognitive explorations of alterations of the latent inhibition mechanism in schizophrenia, a mechanism whereby a repeated experience loses its status of novelty [23]. Instead, time fails to constitute itself as everyday in schizophrenia, i.e., as an intermediate rhythm between stereotyped time and a succession of novelties.

Jaspers cites several first-person descriptions that testify to this lack of sedimentation into a habit, something which is usually achieved via the world of the everyday: "All objects appear so new and startling, I say their names over to myself and touch them several times to convince myself they are real." [24, p. 63]; "Everything looked different - I saw in everything the touch of a divine magnificence. It was as if I had come into a new world, a new existence" [24, p. 63]. Anne, Blankenburg's patient, also reported: "Each day I have to start anew, entirely anew!" $[8$, p. 139].

An examination of the experiences reported by phenomenological psychiatry would seem to indicate that the dimension of normativity and sense of community associated with everydayness is also lacking in schizophrenia. At one extreme, it seems to be reduced to mimesis, which marks a lack of differentiation between self and other associated with the frequent experiences of transitivism reported by patients. At the opposite extreme, we find experiences that demonstrate a loss of any implicit anchoring in an intersubjective horizon, such as is made possible by everydayness. These include not only experiences of 
distortion [10], the loss of affordances [25], and solipsism [26], but also the position of exception that characterizes many psychotic delusions - this can be, for example, a position of divinity, of messiah, of genius, or of a victim persecuted by everyone else. This position of exception points to a position of pure transcendence that cannot be everydayed.

The French psychiatrist Henri Grivois, known for his work on early-onset schizophrenia, reports patient testimony that demonstrates both an experience of confusion with others and a position of exception in a single individual. He proposes to use the term "centrality" for this experience where a person feels they are at once in immediate and mimetic communication with those around them and in a position of exception - since the looks and gestures of everyone else converge onto them. The notion of centrality illustrates well the coexistence, within a single experience, of two extreme poles - lack of differentiation and exception - which are unable to enter into a dialectic through everydayness. "I am the result of everyone. Created, not brought into the world by them, by people, but I reflect myself on them. I am the mirror of Paris. Everyone is in me and I am in everyone. I feel like I'm the only one and I don't like that feeling. The others are together and I'm on the outside" [27, p. 153]. ${ }^{2}$

The failure of this tacit sense of community is also consistent with what Laing has designated as ontological insecurity in psychosis, which he defines as a loss of the sense of reality and identity, both of oneself and of others [28]. According to Laing, this ontological insecurity leads patients to oscillate between two extreme poles: that of a merging of their identity with the identity of others, and that of a complete isolation by which the subject seeks to protect himself from the threat of engulfment.

The dimension of plasticity and adjustment also seems to be affected in schizophrenia. At one end of the spectrum, this impairment of this dimension can be linked to the morbid rationalism described by Minkowski [29], in which the subject seeks to explain his or her perceptions with causal chains that reduce any living dynamism to a material reification. Morbid rationalism consists of a rigid application of formal rules in accordance with a logic that leaves no room for the unexpected or the possible. At the other end of the spectrum, the failure of the process of everydaying tends to result in what the EASE scale refers to as experiences of existential reorientation [11]. Unable to constitute a sphere in which the everyday can be domesticated, the subject is faced with a pure and in-

\footnotetext{
2 Our translation.
}

determinate transcendence, which very often leads either to projects of a mystical and metaphysical nature, or to the refounding of language, science or humanity. This results from a confrontation with a pure transpossibility that cannot take place in any horizon of anticipation which might accommodate it within a framework that has already been established as familiar. In his memoirs, Daniel Paul Schreber recounts the occurrence of such a pure event, which takes on the global significance of a rupture in the history of humanity and in the passage of time itself: "A fateful turn in the history of the earth and of mankind seemed to be marked by the events of one single day distinctly preserved in my memory, on which there was talk of the 'clocks of the world' running out and at the same time a continuous rich stream of rays towards my body accompanied by light phenomena of great splendor" [30, p. 89].

Lastly, the neutral dimension of the everyday brings to mind numerous recent neurocognitive works on the impairment of the attribution of motivational salience in schizophrenia [31], as well as Gestalt-inspired works that highlight difficulties in structuring perception according to a schema of figure and background [32]. Thus, in schizophrenia, there would seem to be a disturbance in the constitution of a neutral and familiar background of perception. Perception would then be subject to a reification that makes things appear in their raw materiality, as though every experience were reduced to raw facts [11].

In Marie Sechehaye's well-known book, a patient named Renée reports her experiences, giving the most evocative description of this phenomenon: "(...) suddenly 'the thing' sprang up. The stone jar, decorated with blue flowers, was there facing me, defying me with its presence, with its existence" [33, p. 56]. At the other extreme, the absence of a familiar background leaves the subject faced with an unassimilable transcendence, such as Binswanger describes in the case of Suzanne Urban: "It is thus that the physiognomy of a fundamentally familiar world, comfortable in spite of worries, changed into a foreign, unusual, hostile physiognomy" [34, p. 38]. Any element of perception is then likely to become salient and significant, thereby giving rise to the feelings of meaning or apophenia [32] characteristic of schizophrenic delusions. In the absence of a process of everydaying that organizes a division between the familiar and the foreign, experience is either reified as a raw fact, or constituted as pure events that no background of familiarity can assimilate and contextualize. These two extreme poles at which perception is affected appear clearly in domains 1 and 5 of the EAWE scale: they include experiences of fragmen-
Troubé 
tation of perception, abnormal perceptual acuity, as well as both deanimation (where what is alive is perceived as inanimate) and perceptual experiences that make inanimate objects appear to be alive and meaningful [12].

It can thus be assumed that the alterations of the prereflective conditions of experience in schizophrenia impede the process of everydaying in its constitutive dimension, which results in a failure to transform the experience of self and world into a ritualized, familiar, and reassuring experience. It seems to us that describing the alterations of subjective experience in schizophrenia as an impairment of everydayness allows us to better consider its implications for the treatment of schizophrenia.

\section{Psychotherapeutic Implications and Possibilities: Everydayness and Narrativity}

By taking into account the specific experience of daily life, we are able to bridge the gap between a phenomenological psychopathology, focused on the transformations of the experience of the world, and a phenomenological psychotherapy that seeks to reweave the fabric of an autonomous and everyday life. The dimensions of everydayness that we have identified here can in fact be constituted as dimensions of a therapeutic work aimed at restoring these different functions of the everyday with the patient.

It seems to us that one of the avenues opened up by these dimensions of everydayness is the psychotherapeutic work of constructing an individual narrative of the everyday, in connection with the phenomenological work on narrativity $[35,36]$ and narrative identity [37]. Since everydayness lies on a pre-reflective level, this construction should not be limited to the explicit content of the narrative. We can assume, based on research regarding the implicit pre-narrative dimension of experience [38], that the organizing and structural elements of the narrative can allow access to the different pre-reflective functions of everydayness.

The work of recounting allows time to be constituted in repetition thanks to the rhythm of the account, which regularly calls upon the same elements while also introducing variations. It introduces a dynamic within the repetition, while at the same time making it possible to assimilate new events and make them familiar.

Constructing an individual narrative also makes it possible to work on the normative and intersubjective dimension of the everyday, because it offers the possibility of playing on different points of view regarding what is

Exploration of Everydayness in

Schizophrenia being recounted. For example, the account is likely to involve characters with different points of view, and since it is addressed to an audience, it invites its narrator to consider another point of view.

Recounting can also facilitate the recovery of the function of plasticity and adjustment of the everyday because it makes it possible to imagine variations and alternatives [39]. It requires a certain flexibility and cannot function with the rigid causal chains that one finds in morbid rationalism. At the same time, the narrative framework provides a structure that makes it possible to order events into a coherent architecture.

Working on narrativity also allows a hierarchy to be established between neutral and salient elements, making it possible to work on the neutrality function of the everyday. The way in which events are recounted makes it possible to distribute their salience differently and in accordance with their place in the account and their relationship with the other elements of the narrative. By linking it to a chain of events, the integration of an event into the account causes it to lose its status of absolute transcendence, but it also makes it possible to place an emphasis on a particular event by virtue of the importance it has played in the subject's history.

It thus seems to us that everydayness, insofar as it is constitutive of experience, invites us to take into consideration a particular form of narrativity, one that is specific to an account of the everyday. Constructing an individual narrative of everyday life could serve as a possible therapeutic mediation for helping the subject reconstruct the dialectic proper to everydayness. Such a therapeutic approach leads us to better question the phenomenological underpinnings of narrativity and its pre-reflective conditions $[40,41]$.

\section{Conclusion}

Taking into consideration a specific experience of the everyday allows us to bridge the gap between research in the field of phenomenology and the objectives of patient care in psychiatry. While attention has certainly been paid to the register of the everyday in phenomenology in recent years, it seems to us that this register has not yet been sufficiently explored.

We have proposed that there is therapeutic value in having patients recount their everyday experiences. This raises the question of the link between the constitution of everydayness and the shaping of experience made possible by narrativity, whose phenomenological underpin- 
nings constitute a rapidly growing field of research today. Moreover, it seems to us that this narrativity of the everyday invites us to consider the social and institutional context, which forms the daily world of the patient and the therapist as an integral part of psychotherapy. The exploration of a specific dimension of everydayness in psychotherapy can thus be situated in line with the consideration of the atmosphere of an institution, as analyzed by Oury and Tosquelles in institutional psychotherapy [42]. In contemporary research, this can lead to a deeper understanding of the links between phenomenology and social psychiatry [43], as well as with other approaches such as Soteria therapy [44].

Finally, a phenomenological understanding of everydayness as a pre-reflective framework of experience could serve to underpin the constitution of a tool for the qualitative and dimensional evaluation of alterations of the everyday in schizophrenia. A preliminary study could thus be based on both EASE and EAWE scale items relating to the experience of the everyday, as well as on the four di- mensions of everydayness identified in this article, in order to provide the empirical basis for an exploratory clinical study.

\section{Acknowledgements}

The author would like to thank Benjamin Farrow for the English translation of this article.

\section{Conflict of Interest Statement}

The author declares that there are no conflicts of interest regarding the publication of this article.

\section{Funding Sources}

No funding was received for this study.

\section{References}

1 Borg M, Davidson L. The nature of recovery as lived in everyday experience. J Ment Health. 2008;17(2):129-40.

2 Larøi F, Van der Linden M. The need for an individualized, everyday life and integrative approach to cognitive remediation in schizophrenia. J Psychother Integration. 2013;23(3): 290-304.

3 Pachoud B. Le soin en famille d'accueil : théories du « care » et quotidienneté. Ann Med Psychol (Paris). 2013;171(8):544-8.

4 Bégout B. La découverte du quotidien. Paris, France: Allia; 2005.

5 Bourdieu P. Le sens pratique. Paris: Éditions de Minuit; 1980.

6 de Certeau M. L'invention du quotidien. Paris: Gallimard; 1990.

7 Berger P, Luckmann T. The Social Construction of Reality. New York: Anchor Books; 1966.

8 Blankenburg W. La perte de l'évidence naturelle. Paris, France: PUF; 1991.

9 Husserl E. The Crisis of European Sciences and Transcendental Philosophy. Evanston: Northwestern University Press; 1970.

10 Binswanger L. Drei Formen missghickten Daseins: Verstiegenheit, Verschrobenheit, Manieriertheit. Tubingen, Germany: Niemeyer; $1956 . \quad$ https://doi. org/10.1515/9783111578071.

11 Parnas J, Møller P, Kircher T, Thalbitzer J, Jansson L, Handest P, et al. EASE: Examination of Anomalous Self-Experience. Psychopathology. 2005 Sep-Oct;38(5):236-58.
12 Sass L, Pienkos E, Skodlar B, Stanghellini G, Fuchs T, Parnas J, et al. EAWE. Psychopathology. 2017;50(1):10-54.

13 Husserl E. Cartesian Meditations. An introduction to phenomenology. The Hague, Netherlands: Martinus Nijhoff; 1960.

14 Heidegger M. Sein und Zeit. Halle, Germany: Max Niemeyer; 1927.

15 Straus E. Psychologie der menschlichen Welt. Gesammelte Schriften. Berlin, Germany: Springer; 1949.

16 Blankenburg W, Mishara AL. First Steps Toward a Psychopathology of "Common Sense". Philos Psychiatry Psychol. 2001;8(4):303-15.

17 Stanghellini G. Disembodied Spirits and Deanimated Bodies: The Psychopathology of Common Sense. Oxford: Oxford University Press; 2004. https://doi.org/10.1093/ med/9780198520894.001.0001.

18 Troubé S. Philosophie de la psychiatrie et phénoménologie du quotidien : les bouleversements de l'expérience ordinaire dans la clinique des psychoses. Rev Synth. 2016; 137(1/2):61-86

19 Troubé S. Psychopathologie phénoménologique du quotidien. De la genèse de la quotidienneté à ses dimensions cliniques. In: Englebert J, Cormann G, Adam C, editors. Psychopathologie phénoménologique. Dépassement et ouverture. Volume 2. Paris, France: Vrin; 2019. pp. 123-40.

20 Maldiney H. Penser l'homme et la folie. Grenoble, France: Jérôme Million; 2007.
21 Ratcliffe M. Varieties of temporal experience in depression. J Med Philos. 2012 Apr;37(2): 114-38.

22 Sass L, Pienkos E. Space, time and atmosphere: a comparative phenomenology of melancholia, mania and schizophrenia, part II. J Conscious Stud. 2013;20(7-8):131-52.

23 Rascle C, Mazas O, Vaiva G, Tournant M, Raybois O, Goudemand M, et al. Clinical features of latent inhibition in schizophrenia. Schizophr Res. 2001 Sep;51(2-3):149-61.

24 Jaspers K. General Psychopathology. Baltimore: Johns Hopkins University Press; 1997.

25 Sass LA, Parnas J. Schizophrenia, consciousness, and the self. Schizophr Bull. 2003;29(3): 427-44.

26 Parnas J, Sass A. Self, Solipsism, and Schizophrenic Delusions. Philos Psychiatry Psychol. 2001;8(2-3):101-20.

27 Grivois H. Grandeur de la folie. Itinéraire d'un psychiatre iconoclaste. Paris, France: Robert Laffont; 2012.

28 Laing RD. The Divided Self. London: Tavistock; 1959

29 Minkowski E. Au-delà du rationalisme morbide. Paris, France: L'Harmattan; 1997.

30 Schreber DP. Memoirs of my nervous illness. New York: The New York review of books; 2000.

31 Nelson B, Whitford TJ, Lavoie S, Sass LA. What are the neurocognitive correlates of basic self-disturbance in schizophrenia? Integrating phenomenology and neurocognition: Part 2 (aberrant salience). Schizophr Res. 2014 Jan;152(1):20-7. 
32 Conrad K. Die beginnende Schizophrenie. Bonn: Edition Das Narrenchiff; 2002.

33 Sechehaye M. Autobiography of a schizophrenic girl: the true story of "Renée". New York: Meridian; 1968.

34 Binswanger L. Le cas Suzanne Urban : Étude sur la schizophrénie. Bruges, Belgique: Desclée de Brouwer; 1957.

35 Jongepier F. Towards a constitutive account of implicit narrativity. Phenomenol Cogn Sci. 2016;15(1):51-66.

36 Mishara AL. Narrative and psychotherapythe phenomenology of healing. Am J Psychother. 1995;49(2):180-95.

37 Ricœur P. Oneself as Another. Chicago: University of Chicago Press; 1992.
38 Applebaum MH. Intentionality and Narrativity in Phenomenological Psychological Research: Reflections on Husserl and Ricœur. Indo-Pac J Phenomenol. 2014;14(2):1-19.

39 Ricœur P. Time and narrative. Chicago: University of Chicago Press; 1990.

40 Gallagher S. Self narrative in schizophrenia. In: Kircher T, David A, editors. The Self in Neuroscience and Psychiatry. Cambridge: Cambridge University Press; 2003. https:// doi.org/10.1017/CBO9780511543708.017.

41 Zahavi D. Minimal Self and Narrative Self. In: Fuchs T, Sattel HC, Henningsen P, editors. The Embodied Self: Dimensions, Coherence and Disorders. Stuttgart, Germany: Schattauer; 2010.
42 Chaperot C, Altobelli A. Psychiatrie et ambiance. Evol Psychiatr (Paris). 2014;79(3):54155.

43 Thoma S, Fuchs T. Inhabiting the shared world. Phenomenological considerations on sensus communis, social space and schizophrenia. In Hippolito I, Gonçalves J and Pereira J, editors. Schizophrenia and Common Sense - Explaining the Relation between Madness and Social Values. Uitgever: Springer; 2018.

44 Nischk D, Dölker C, Rusch J, Merz P. From theory to clinical practice: A phenomenologically inspired intervention for patients with schizophrenia. Psychopathology. 2015 48:(2)127-36. 